\title{
Mediterranean Diet and Physical Activity for Successful Aging: An Update for Nutritionists and Endocrinologists
}

\author{
Evelyn Frias-Toral ${ }^{1, *}$, Sebastian Chapela ${ }^{2,3}$, Maria de los Angeles Carignano ${ }^{4} \mathbb{(}$, Dino Moretti ${ }^{5} \mathbb{D}^{\mathbb{D}}$, \\ Andres Martinuzzi ${ }^{6}{ }^{\oplus}$, Dolores Rodríguez-Veintimilla ${ }^{7}$, Mery Guerrero ${ }^{7}$, Gabriella Pugliese ${ }^{8,9}$, \\ Giovanna Muscogiuri ${ }^{9,10,11}$ and Luigi Barrea ${ }^{8,11}$ (D)
}

check for updates

Citation: Frias-Toral, E.; Chapela, S.; de los Angeles Carignano, M.; Moretti, D.; Martinuzzi, A.; Rodríguez-Veintimilla, D.; Guerrero, M.; Pugliese, G.; Muscogiuri, G.; Barrea, L. Mediterranean Diet and Physical Activity for Successful Aging: An Update for Nutritionists and Endocrinologists. Endocrines 2021, 2, 366-383. https://doi.org/ 10.3390/endocrines2040034

Academic Editor: Antonio Brunetti

Received: 1 July 2021

Accepted: 24 September 2021

Published: 29 September 2021

Publisher's Note: MDPI stays neutral with regard to jurisdictional claims in published maps and institutional affiliations.

Copyright: (C) 2021 by the authors Licensee MDPI, Basel, Switzerland. This article is an open access article distributed under the terms and conditions of the Creative Commons Attribution (CC BY) license (https:/ / creativecommons.org/licenses/by/ $4.0 /)$.
1 School of Medicine, Universidad Católica Santiago de Guayaquil, Av. Pdte. Carlos Julio Arosemena Tola, Guayaquil 090615, Ecuador

2 Departamento de Bioquímica Humana, Facultad de Medicina, Universidad de Buenos Aires, Buenos Aires C1121ABE, Argentina; sebachapela@gmail.com

3 Hospital Británico de Buenos Aires, Equipo de Soporte Nutricional, Buenos Aires C1280AEB, Argentina

4 Intensive Care Unit, Sanatorio Franchín, Bartolomé Mitre 3565, Buenos Aires C1201AAO, Argentina; angiecarignano@gmail.com

5 Hospital “Eva Perón”, Avenida San Martín, G. Baigorria 1645, Santa Fe S2152EDD, Argentina; morettidino@hotmail.com

6 Nutrihome, Neuquén 8316, Argentina; alnmartinuzzi@gmail.com

7 Clinical Nutrition and Dietetics Service, SOLCA Guayaquil, Av. Pedro Menendez Gilbert, Guayaquil 090505, Ecuador; dra.rodriguezv@yahoo.com (D.R.-V.); meryguerrerot@hotmail.com (M.G.)

8 Centro Italiano Per la Cura e il Benessere Del Paziente Con Obesità (C.I.B.O), Endocrinology Unit, Department of Clinical Medicine and Surgery, University Federico II, 80131 Naples, Italy; robiniapugliese@gmail.com (G.P.); luigi.barrea@unipegaso.it (L.B.)

9 Unit of Endocrinology, Dipartimento di Medicina Clinica e Chirurgia, Federico II University Medical School of Naples, 80131 Naples, Italy; giovanna.muscogiuri@gmail.com

10 Cattedra Unesco "Educazione Alla Salute e Allo Sviluppo Sostenibile", University Federico II, 80131 Naples, Italy

11 Dipartimento di Scienze Umanistiche, Università Telematica Pegaso, Via Porzio, Centro Direzionale, Isola F2, 80143 Napoli, Italy

* Correspondence: evelyn.frias@cu.ucsg.edu.ec

Abstract: The constant advancement in the medical field has allowed for the diagnosis and treatment of several health conditions. It has also contributed to increasing the average human lifespan, which is considered an outstanding achievement in history. Nevertheless, the impact of this in an everincreasing aged population with chronic diseases and, most of the time, with limited and poor quality of life was not considered. Thus, it is imperative to establish strategies to age successfully. In order to do have a better understanding of this crucial issue, this review will analyze the endocrine changes in the elderly. It will present common conditions found in this population, chronic inflammation, and oxidative stress. Additionally, we will explain aging-related metabolic and physical performance decline related to hormone changes and lifestyle modifications. We will propose the Mediterranean diet and some specific guidelines about physical activity as part of the plan to have an active and successful aging process.

Keywords: aging; hormones changes; physical activity; the Mediterranean diet

\section{Introduction}

In daily practice with outpatients or inpatients, it is pretty common to find a growing number of multipathological, polymedicated, and frail elderly patients; it could be said that this is the rule [1]. Therefore, if there is agreement that aging successfully is the goal to follow, the fundamental question will become how to achieve it. Knowing this reality, it can be of great help in the discussions with our patients and their families (the criteria of the original definition by Rowe and Kahn) [2] to consider what defines successful aging, 
that is: (1) low probability disease and associated disability; (2) elevated cognitive and physical functioning; and (3) being actively engaged in life. Therefore, the critical question will be how this could be achieved.

Increasing life expectancy is celebrated as one of humanity's most outstanding successes. However, the other side of the coin is that aging is the leading risk factor for the most common chronic non-communicable diseases (cardiovascular diseases, strokes, dementia, cancers, among others). In other words, the advance in life expectancy was not accompanied by a similar improvement in health expectancy. Consequently, over the past decades, the gain in life years has been followed by additional years of chronic and poor health. As a result, the most significant proportion of the total health care budget expenditure is now concentrated in the last years of life [3].

The population's aging is a global, medical, and sociodemographic problem. In response to this, the World Health Organization (WHO) promotes healthy aging, a concept that encompasses maintaining the functional capacity to achieve well-being in old age and operates through the Decade of Healthy Aging 2020-2030 program [4].

Aging is characterized by a progressive deterioration of physiological functions over time. Molecular and cellular damage could summarize our understanding of this process. While growing old is part of our lives, this process is not the same in all individuals [5]. The aging trajectory is malleable and can be modified by lifestyle and dietary habits. Additionally, numerous metabolic adjustments, especially those related to hormonal actions, are associated with lifestyle changes as people age [6]. The Mediterranean diet and physical exercise are sustainable and evidence-based interventions that could reduce morbidity in old age with significant economic and social benefits and favor individual well-being [7].

This review will address the metabolic, hormonal, and pathophysiological changes that age brings and the benefits of the Mediterranean diet and physical exercise for active and successful aging to add life to the years ahead.

\section{Endocrine Changes in the Elderly Subject}

Age-related hormonal changes occur in human physiology and have been well described; however, how these changes impact health and/or disease is not yet completely known.

The differentiation between physiological adjustments that can be beneficial to the aging process, from changes that are considered to be the main alterations in the development of metabolic complications and chronic diseases associated with the elderly, is necessary. This distinction is needed mostly to develop medical interventions targeted to specific hormone disorders to achieve longevity and a better quality of life $[6,8]$.

Like the ones involved in nutrition, reproduction, growth, and metabolism, most endocrine axes show a decrease in hormonal secretion with aging. Also, a reduction in tissues sensitivity to their action (e.g., insulin resistance) changes circadian rhythms and biological availability (e.g., sex hormones, corticosteroids), and is responsible for the clinical manifestations identified in this population [8].

The loss of function in the growth axis, called somatopause, in the reproductive system, named menopause and andropause, and the ones involving the adrenal gland or adrenopause, are a growing health concern, as the aging population is continuously growing [9].

Interestingly, these complex alterations in hormonal networks are related to the decline in physiologic functions and the onset of chronic diseases such as frailty, sarcopenia, osteoporosis, obesity, hypertension, diabetes, hyperlipidemia, atherosclerosis, and immune functions reduction. (Table 1) Additionally, these endocrine alterations are prevalent in patients that develop degenerative brain disease with cognitive impairment and a general decline in brain function [6]. 
Table 1. Summary of metabolic changes and clinical manifestations in the elderly.

\begin{tabular}{|c|c|c|c|}
\hline Axis & Hormones & Changes with Aging & Clinical Manifestations \\
\hline $\begin{array}{l}\text { Hypothalamic-Pituitary- } \\
\text { Adrenal Axis } \\
{[6,9,10]}\end{array}$ & DHEA/DHEA-S & $\begin{array}{l}\text { Peak second decade } \\
\text { Decrease since second decade } 2 \text { to } \\
3 \% \text { per year } \\
\text { >decrease DHEA-S than DHEA } \\
\text { > decrease in men than women }\end{array}$ & $\begin{array}{l}\text { Increase: } \\
\text { Body fat mass } \\
\text { Waist-to-hip ratio } \\
\text { Risk of CVD } \\
\text { Risk of ischemic heart disease } \\
\text { Decrease: } \\
\text { Lean body mass } \\
\text { V_O2max } \\
\text { Bone density }\end{array}$ \\
\hline $\begin{array}{l}\text { Hypothalamic-Pituitary- } \\
\text { Thyroid Axis } \\
{[11,12]}\end{array}$ & TSH-T3-T4 & $\begin{array}{l}\text { High Prevalence of TPO antibodies } \\
\text { TSH levels differs depending on } \\
\text { iodine ingestion }\end{array}$ & $\begin{array}{l}\text { Increase: } \\
\text { Subcutaneous and visceral fat } \\
\text { Risk for obesity } \\
\text { Risk for type } 2 \text { diabetes } \\
\text { High blood pressure } \\
\text { Triglycerides } \\
\text { Risk of metabolic syndrome } \\
\text { Decrease: } \\
\text { Insulin sensitivity } \\
\text { Muscle mass } \\
\text { Strength } \\
\text { Bone density }\end{array}$ \\
\hline \multirow[t]{2}{*}{$\begin{array}{l}\text { Hypothalamic-Pituitary- } \\
\text { Gonadal Axis } \\
{[6,13-16]}\end{array}$} & Testosterone & $\begin{array}{l}\text { Decrease since third/fourth decade } \\
1 / 2 \text { per year in men and women } \\
\text { Clinical effects have more impact } \\
\text { in men } \\
\text { Total } \mathrm{T} / \text { free } \mathrm{T} \text { changes with aging }\end{array}$ & $\begin{array}{l}\text { Increase: } \\
\text { Subcutaneous and visceral fat } \\
\text { Risk for obesity } \\
\text { Risk for type } 2 \text { diabetes } \\
\text { High blood pressure } \\
\text { Triglycerides } \\
\text { Risk of metabolic syndrome } \\
\text { Decrease: } \\
\text { Insulin sensitivity } \\
\text { Muscle mass } \\
\text { Strength } \\
\text { Bone density }\end{array}$ \\
\hline & $\begin{array}{l}\text { Reproductive Hormones } \\
\text { (FSH/LH/Estrogens) } \\
{[8,9] .}\end{array}$ & $\begin{array}{l}\text { Decrease since } 5 \text { th or } 6 \text { th decade } \\
\text { Big disease burden } \\
\text { Follicular depletion }\end{array}$ & $\begin{array}{l}\text { Impairment: } \\
\text { Reproductive system } \\
\text { Osteoporosis } \\
\text { CVD } \\
\text { Cerebrovascular diseases } \\
\text { Vasomotor symptoms } \\
\text { Sleep and mood disorders } \\
\text { Decreased libido } \\
\text { Cognition and memory }\end{array}$ \\
\hline
\end{tabular}

\section{Increase:}

Risk for obesity

Declination of amplitude more than

Visceral adipose tissue

frequency of pulsation

Somatotropic axis [6]

GH-IGF-1
Peak at puberty

Decrease since puberty 1 to $2 \%$ per year
Risk of metabolic syndrome

Risk of CVD

Decrease:

Lean body mass

Strength

Bone density

Abbreviations: DHEA Dehydroepiandrosterone; DHEA-S dehydroepiandrosterone sulfate; CVD cardiovascular disease; TSH thyroidstimulating hormone; T3 Triiodothyronine; T4 Thyroxine; TPO Thyroid peroxidase; FSH Follicle-stimulating hormone; LH luteinizing hormone; GH Growth Hormone; IGF-1 Insulin-like Growth Factor-1. 
Undoubtedly, a decrease in quality of life is the course, leading to an increase in the economic burden on public health systems [6].

As aging itself is the consequence of several intertwined and multifactorial processes, so is the declination of the endocrine axis.

The theory that involves oxidative stress in the aging process has been proposed to be implicated in endocrine system dysfunction. Endocrine glands and the hypothalamicpituitary axis probably aged secondary to free radical excesses in the central nerve system. The following section will address oxidative stress's role in the pathophysiology of these changes [17].

\subsection{Hypothalamic-Pituitary Unit}

The hypothalamic-pituitary unit acts as the regulator of many systems and endocrine axesIts hormonal secretion and feedback mechanisms are responsible for controlling circadian cycles, stress adaptation, energy, water, electrolyte equilibrium, sleep and wake cycles, sexual behavior, and conceptive periodicity. This regulation of homeostasis requires continuous adjustments that go on throughout the entire lifespan [8].

\subsubsection{Hypothalamic-Pituitary-Adrenal Axis}

Dehydroepiandrosterone (DHEA) and its sulfate DHEA-S are the most synthesized of all adrenal steroids and are considered the precursors of androgens and estrogens; consequently, the declination in DHEA and DHEA-S levels result in a profound dysregulation of the overall hormonal profile.

The main site of production, with about $75 \%$ to $90 \%$ of DHEA, is the adrenal cortex. The rest of the production is done in the ovaries, testes, and brain. DHEA is then converted to DHEA-S. These adrenal hormones show their greatest secretion around the second decade and then decline $2 / 3 \%$ per year, both in women and men [5]. Noticeably, some studies showed that aging women had a higher cortisol/DHEA-S ratio than men, secondary to less negative feedback on cortisol production. This modification allows a better response to corticotropin-releasing hormone $(\mathrm{CRH})$, and it is thought to be beneficial regarding DHEA-S effects on metabolic and psychiatric changes [10].

Several benefits have been postulated for these steroids: immune protection, anticancer, anti-aging and neurostimulation effects [18]. What is more, cross-sectional studies showed a correlation between DHEA-S levels and metabolic and psychological impairments like type 2 diabetes (T2D), depression, cardiovascular disease (CVD), and even Alzheimer's [9].

\subsubsection{Hypothalamic-Pituitary-Thyroid Axis}

Thyroid disturbance is widespread in all groups of people, and its prevalence increases with age. Even though there are no unifying models on the diagnosis of thyroid disorders to treat them, it is clear that aging increases the incidence of slightly elevated and suppressed TSH [12].

Many studies suggest that these changes may be an adaptive mechanism to maintain homeostasis. The TSH/T4 relationship was shown to be heritable and associated with individual gene variations in studies with twins and genetic analyses. One study, for example, observed slightly elevated TSH in centenarians and their elderly offspring, confirming some heritage in thyroid function [12]. Iodine disponibility during life also appears to impact age-related thyroid function [8]. Different TSH levels related to age have been found in populations with higher rather than low iodine intake. Recent data suggest that in a population with sufficient iodine ingestion, TSH levels will show a mild increase with age; the interpretation is conflicting as in vivo human data lacks the exact meaning of these changes. Currently, the interpretation of an elevated THS level in populations with stable iodine ranks may be a sign of lower thyroid hormones [13].

As thyroid function is assessed, primarily by measurement of TSH, a controversy exists regarding whether the actual range of TSH levels should be applied to all ages; this 
is of greatest importance when TSH levels are used to diagnose thyroid syndromes and to guide hormone replacement treatment [12].

The NHANES survey, along with other 2 large population-based studies, showed that subjects $>70$ years old had a high prevalence of TPO antibodies -up to $30 \%$ - that correlated with higher levels of TSH and total thyroxine decrease in the same population [12].

When studying thyroid disorders, it is possible to find overt hypo and hyperthyroidism; however, subclinical thyroid alterations are more common [11].

Undoubtedly, overt hypo and hyperthyroidism require treatment and are related to incremented morbidity and mortality, mostly related to CVD and Atrial Fibrillation (AF). Nevertheless, a distinction must be made for subclinical disorders. Subclinical hypothyroidism did not associate with CV or all-cause mortality in a large meta-analysis [19]; subclinical hyperthyroidism, on the other hand, increased $\mathrm{CV}$ morbidity by increasing $\mathrm{AF}^{\prime} \mathrm{s}$ risk and coronary heart disease (CHD) [11].

\subsubsection{Hypothalamic-Pituitary-Gonadal Axis}

The activities promoted by this axis are related, mainly, to its reproductive and anabolic effects that increase muscle protein synthesis, muscle mass and strength, and bone mineral density.

Andropause and Late-Onset Hypogonadism ( $\mathrm{LOH})$

Testosterone (T) decline slowly begins at the third/fourth decade of life, and it will continue throughout life at a rate of $1 \% / 2 \%$ per year. This alteration occurs in men and women, but the clinical effects in its decrease have less impact, as $\mathrm{T}$ concentration in the female population is about $10 \%$ of that of men. While $\mathrm{T}$ declines, sex hormone-binding globulin (SHBG) grows [13], pointing to a decline of $\mathrm{T}$ endogenously produced as the relationship of total $\mathrm{T} /$ free $\mathrm{T}$ changes [6].

When low serum concentrations of $\mathrm{T}$ are associated with symptoms of hypogonadism, we are in the presence of $\mathrm{LOH}$. $\mathrm{LOH}$ has a prevalence of 2 to 3\%, as reported by the European Male Aging Study (EMAS). The most frequent symptoms are sexual dysfunction and lack of sexual desire; physical (frailty, muscle weakness, osteoporosis) and psychological manifestations (depression, fatigue) complete the diagnosis [20].

This syndrome has shown a correlation with obesity and T2D; on the other hand, hyperinsulinemia and insulin resistance and obesity cause T reduction at a testicular level creating a vicious circle that negatively impacts muscle and adipose tissue function $[14,15]$. CVD and obstructive pulmonary disease are also among the metabolic manifestations found when $\mathrm{T}$ levels decline, increasing the risk of all-cause mortality [16].

\section{Menopause}

Menopause is due to the decline in reproductive hormones, among several other physiological changes occurring in women's fifth or sixth decade of life. The hormonal alterations are accompanied by ovarian follicle depletion and clinical sequelae like osteoporosis, CVD and cerebrovascular diseases, vasomotor symptoms, sleep and mood disorders, and decreased libido. Cognition and memory can also be affected. These affect women's quality of life deeply and is a big disease burden [8,9].

\subsubsection{Hypothalamic Pituitary Axis}

Somatopause

The declination of the Growth Hormone (GH) and the Insulin-like Growth Factor (IGF-1) are called somatopause. GH is synthesized by hypophysis and is in charge of the growth of almost every human tissue. It is released in a pulsatile way, peaked in puberty and declining at $1 \%$ to $2 \%$ per year. IGF- 1 behaves in the same fashion and acts as a mediator of cellular growth [6].

GH and IGF-1 decrease have, as with the previous hormones, profoundly affected metabolic health. It increases visceral adipose tissue and leads to obesity; it is related 
to lean body mass and bone density deterioration and increments CVD and metabolic syndrome risks [6].

\section{Chronic Inflammation and Oxidative Stress in the Elderly Subject}

Aging comprises several deterioration processes of homeostasis. Moreover, it is accompanied by the impairment of several physiological systems, including the immune system, within other failing systems. Fuente and Miquel proposed an integrative theory of aging, where oxidation, mitochondria malfunction of differentiated cells, and pleiotropic genes are the leading causes of aging [21].

The homeostatic loss and misfunctioning systems result from injury caused by the high reactivity of the free radicals and reactive oxygen species (ROS) produced on the biomolecules of these cells. The mitochondria DNA (mtDNA) is the first target of this oxidation. Because of this damage, the post-mitotic cells could not repair nor regenerate these "broken" organelles [21]. Also, age epigenetic changes include alterations in DNA methylation patterns, post-translational alteration of histones, and chromatin remodeling [22].

Oxidative stress is a well-known imbalance between ROS and nitrogen species (RNS) and reduced antioxidant defenses. Furthermore, reduced levels of glutathione (GSH) have been found in the elderly. It is essential to highlight that the human organism is continuously exposed to many ROS and RNS from pathophysiological and physiological conditions. These reactive species are slowly accumulated in cells by damaging different sources (lipids, proteins, and DNA). The antioxidant pathways are complex defense systems developed through evolution to protect the human organism from this accumulation and oxidative damage. As part of the antioxidant network, we could find various enzymes like catalase, glutathione peroxidase, superoxide dismutase, and several non-enzymatic antioxidants, like GSH, vitamins A, C, and E, carotenoids, selenium, and zinc [23].

In the mitochondrial theory of aging, this organelle is incorporated as a critical component that regulates aging. Because it seems electrons from the mitochondrial electron transport chain (ETC) are responsible for producing ROS, which injures components of the same ETC and alters mtDNA, leading to a recurring increase in intracellular ROS levels and a deterioration in mitochondrial function [24].

As we had explained before, an essential part of the aging process is a chronic imbalance between pro-inflammatory and anti-inflammatory networks [22]. In several studies, levels of pro-inflammatory mediators were high in the elderly, even in the absence of acute inflammatory response (e.g., acute infection) or other systemic stress events. This chronic inflammation situation is common in many aging-related conditions. Thus, inflammatory and oxidative stress leads to severe injury of cellular components (e.g., proteins, lipids, and DNA), contributing to the age-related decline of physiological capacities. This process is more evident in cells from different systems (nervous, endocrine, and immune). It undoubtedly describes their functional losses observed during aging, resulting in higher morbidity and mortality [22]. It is necessary to highlight that physiological organismal, and cellular integrity loss are the primary risk factor for several pathologies, such as cancer, T2D, CVD, and the well-known metabolic syndrome [22]. A continuing accumulation of impairment originated from oxidative stress, like glycated products, oxidized proteins, and lipid peroxidation, leads to a degeneration of neurons, which is frequently found in neurological diseases. Vascular lesions also characterize cerebrovascular diseases, which are recognized for cognitive decline and dementia in old age. Moreover, in brain tissue cells, ROS are produced by microglia and astrocytes and might lead to neuroinflammation and cell death, triggering neurodegeneration and memory loss [23].

Also, there is data indicating a decrease of endogenous antioxidants in aging. The critical drop of GPx activity in older people is crucial for developing ROS neutralization since this enzyme catalyzes hydrogen peroxide $\left(\mathrm{H}_{2} \mathrm{O}_{2}\right)$ [25]. The alteration of this enzyme's activity with aging looks to be very specific, not only in tissues but also in cellular compartments. For example, GPx declines significantly with age in the cytosol but increases in 
mitochondria, revealing adaptations caused by augmented ROS production in mitochondria along with the progression of aging. Thus, GPx activity was reversely associated with Malondialdehyde (MDA) and protein carbonyl (PCO) [5] levels, both crucial biomarkers of oxidative stress, implying that a reduction in endogenous defense might raise oxidative damage, which can lead to an enzymatic inactivation in a vicious cycle [26]. We must point out that the GPx activity could also be reduced due to the lack of its most fundamental cofactor, selenium [23].

Systemic low-grade inflammation (LGI) related to aging is demarcated by a two or threefold increase in acute-phase proteins and cytokines' plasma concentration [27]. The molecular and biological significance of systemic LGI in chronic disease is not fully understood; nevertheless, it is well associated with age-related diseases including atherosclerosis, metabolic syndrome, T2D, Alzheimer's disease, and vascular dementia [28,29].

C-reactive protein plays a part in activating anti-inflammatory cytokines in circulating monocytes and suppressing pro-inflammatory cytokines in tissue macrophages. The primary cytokines in this inflammatory cascade are tumor necrosis factor $\alpha$ (TNF- $\alpha$ ) and interleukin $1 \beta$ (IL-1 $\beta$ ) [30], which are considered pro-inflammatory cytokines. TNF- $\alpha$ and IL-1 $\beta$ stimulate interleukin 6 (IL-6) generation, which has both actions a pro-inflammatory and an anti-inflammatory cytokine. IL- 6 blocks the production of TNF- $\alpha$ and IL-1 $\beta$, inducing the discharge of soluble TNF- $\alpha$ receptors (sTNF-R), and might be the main inducer of hepatocyte-derived acute-phase proteins, several of which have anti-inflammatory qualities. TNF- $\alpha$ and IL- $1 \beta$ represent classic pro-inflammatory cytokines, although sTNF-R and interleukin 10 are anti-inflammatory cytokines [24].

As a fundamental aspect for CVD and well-being status in the elderly, the importance of vascular aging has been extensively studied. Reduced endothelial vasodilation is an initial sign of arterial aging that frequently leads to clinical manifestations of vascular malfunction [31]. It is the first step of CVD and determines vascular outcomes in the elderly population [32]. The aging of vasculature is generated by an excess of ROS, superoxide, and hydrogen peroxide, and affects the vasodilatory activity of nitric oxide (NO), and facilitates the production of the deleterious radical peroxynitrite [33]. El Assar et al. well describes this inflammatory and oxidative process in the vascular system [28]. As we previously said, a reduced antioxidant response is frequently presented, but in this case, it is facilitated by erythroid-2-related factor-2 (Nrf2); also, down-regulation of mitochondrial manganese superoxide dismutase (SOD2) plays an essential part in chronic oxidative stress in aged vessels [23].

It is imperative to highlight that this situation leads to aging and the development of cancer. As Khansari et al. [27], described, free radicals might lead to DNA damage and mutation, these can be predisposing factors for cancer and other related disorders. In addition, free radicals will react with cell membrane fatty acids and produce lipid peroxides, and their accumulation could produce carcinogenesis agents. In this case, cell injury due to lipid peroxidation can permanently reduce fluidity and elasticity of the membrane and the cell rupture [34].

As we can see, multiple systems are affected by chronic inflammatory states and oxidate imbalance (Figure 1). So, they are key factors to understand aging, and this knowledge is also crucial to be considered as a potential intervention measure in future therapies for these inflammatory and oxidative states [35]. 


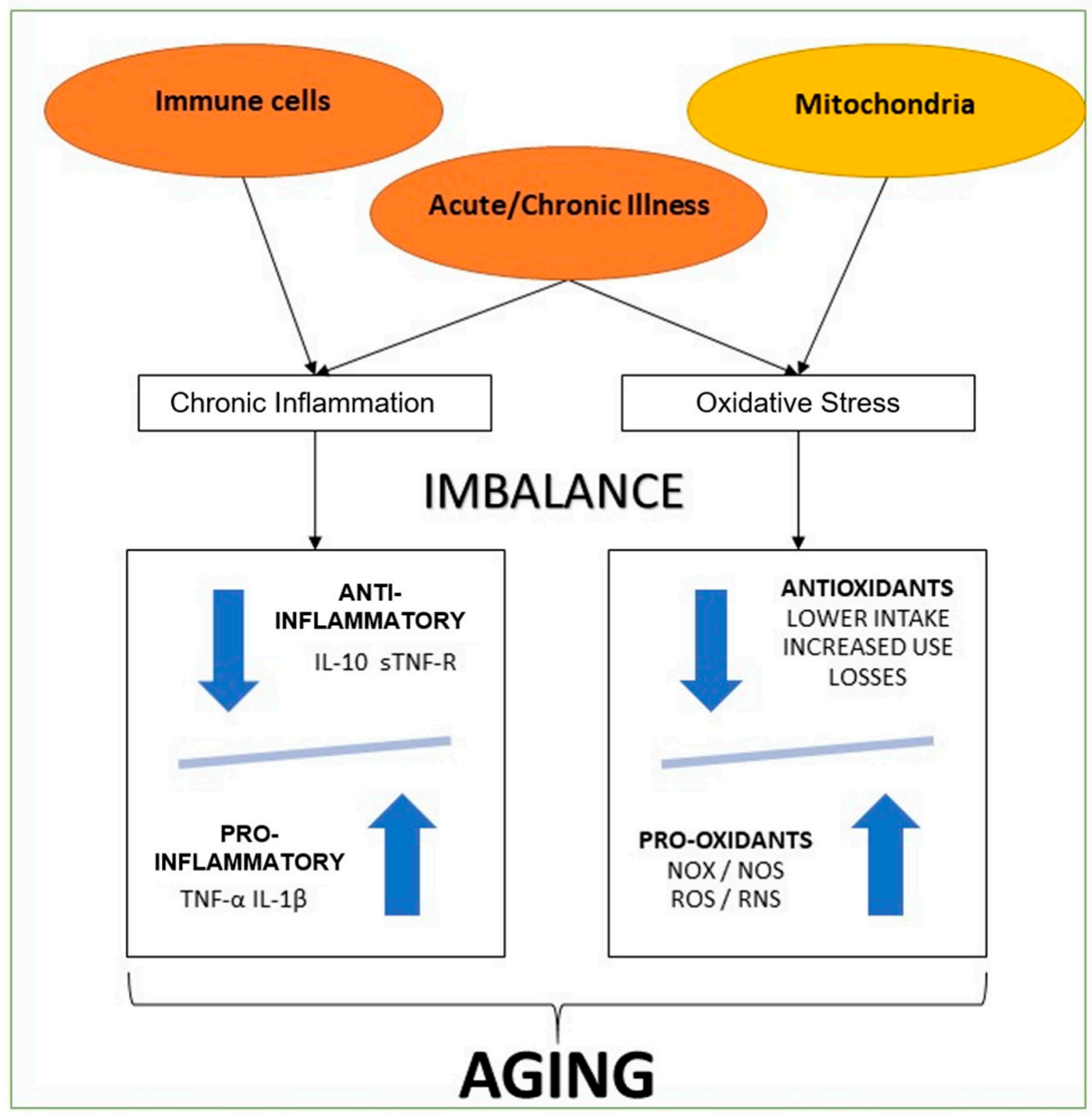

Figure 1. Summary inflammation and oxidative process of aging. The present graphic comprises the most accepted theories of aging. Immune cell and mitochondrial disfunction, with concomitant chronic or acute illness. Two metabolic ways of harm, both marked with a profound imbalance. One through cytokines, with lower plasma levels of anti-inflammatory markers (Il-10: Interleukin 10, sTNF-R: Soluble tumor necrosis factor receptor) and increased pro-inflammatory markers (IL-1 $\beta$ : Interleukin 1 beta, TNF- $\alpha$ : Tumoral necrosis factor-alpha). The other through oxidants imbalance, lower antioxidants levels due to lower nutritional intake, increased use due to acute or chronic illness, and losses through digestive and renal dysfunctions. Increased oxidants plasma levels (NOX: NADPH oxidases, NOS: nitric oxide synthase, ROS: Reactive oxygen species, RNS: Reactive nitrogen species) due to mitochondrial dysfunction and inflammatory states triggered due to acute or chronic illness.

\section{Metabolic and Physical Performance Decline of Aging-Related to Hormone Changes and Lifestyle Changes}

\subsection{Physical Activity in the Elderly}

Physical activity among older adults has multiple benefits but is first essential to determine the recommended activity. Physical activity may reduce inflammation and oxidative stress through multiple mechanisms, including the reduced formation of ROS and the accelerated production of DNA-repairing enzymes and antioxidant proteins; furthermore, it can moderate oxidative stress by decreasing TNF- $\alpha, \mathrm{C}$-reactive protein, and interleukin-6 [36-38]. There is conflicting evidence on the effect of physical activity and hormone levels, depending on the kind and length of activity, which can increase the levels of dehydroepiandrosterone and testosterone, but there is no clear evidence. Moreover, 
growth hormone is increased in older persons in response to short-term exercise. However, in the postexercise recovery period, the reversal of this hormone back to resting values occurs quicker in older individuals than in younger individuals, and the increase during exercise appears to be dependent on exercise intensity [6]. In more recent years, the beneficial effect of exposure to low-grade potentially damaging conditions or very low doses of toxic compounds has been conceptualized as "preconditioning" and "hormesis" [2,39]. In this respect, healthy nutrition, mainly as given by the Mediterranean diet and planned physical exercises, are determinant resources to deeply modify this systemic inflammatory balance on a long-term scale by decreasing the age-related increment of inflammatory molecules and by promoting adaptive anti-inflammatory changes $[2,3,39,40]$.

The WHO in 2020 advised that the elderly population should do mixed compound exercises at the moderate or more vigorous intensity at least three days weekly [41]. That publication suggests that people can begin with short exercise sets and increments over time. Before beginning with light-intensity exercises, previous medical counseling is not needed for adults with no contraindications [41]. However, in the same guideline, it is stated that patients with chronic diseases may expect directions on the type of exercises according to their requirements, strengths, conditions/complications, medicines, and treatment program from a physical therapist or healthcare specialist [41]. The Department of Health of the United Kingdom recommends that the elderly should strive to be active every day, and to aim for at least $150 \mathrm{~min}$ of moderate-intensity activity per week. Those who were already routinely active at moderate intensity can reach similar advantages with 75 min of strong-intensity activity distributed during the week [42]. These individuals describe multiple benefits from physical exercise; positive lifestyle adjustments like routine aerobic and endurance workout programs improve several age-related illnesses [6]. WHO claims that physical activity is necessary to improve functional capacity and to limit falls and fall-associated lesions, frailty, and osteoporosis [41]. A meta-analysis published in 2021 that included studies with people older than 65 years showed that resistance training made significant changes in fat mass (Effect Size $=0.41$ [95\% CI: 0.23 to 0.59], $p=0.001$ ) and muscle mass [43]. The same study showed benefits in agility, balance, gait speed, and functional strength [43]. There are also studies where frailty status is improved with an exercise program [44]. In advanced age, physical activity is effective since it decreases sarcopenia, increases robustness, and prevents or delays the development of disability [45]. In an RCT, older people engaged in resistance training showed an increase in the number of steps taken daily, lower-limb muscle strength, and a significant decrease in frailty scores [46].

The positive effect of physical exercises among the elderly is not only shown to improve physical status. In a meta-analysis with people diagnosed with Alzheimer disease where 13 controlled trials were analyzed, it was shown that physical activity improved the Mini-Mental State Examination (Standard Media Deviation = 1.12; CI = 0.66-1.59; $p=0.000$ ) [47]. In a cross-sectional study with 2345 healthy participants, physical activity was related to life satisfaction (measured with a single question) and happiness (also measured with a simple question) [48]. Also, in the same study, satisfaction and happiness associated with physical activity increased with [48]. Interestingly in this study, most of the older adults had high active physical activity $(44.01 \%)$, and having this amount of activity was a predictor of life satisfaction and happiness [48]. In a 2016 survey, 1504 elders aged between 65 to 80 years with or without disabilities were assessed for stress and depression using Patient Health Questionnaire-9 and quality of life using the EuroQol-5 Dimension [49]. Patients without disabilities had more physical activity, and stress and anxiety/depression levels were higher in those with disabilities [49]. In an experimental randomized controlled study, patients were interviewed before and after a physical activity program. There was a decrease in the depression scale and in eight sub-categories and two aspects of the SF 36 Quality of Life Questionnaire [50]. Additionally, there are reports where regular exercises diminish the probability of developing chronic conditions like CVD, T2D, and some cancers [50,51]. In the same survey, in 6933 adults, it was observed that there were $0.32 \%$ longer leukocyte telomeres with an increment of one hour per week [52]. 
Finally, in a cross-sectional study between 1999-2002 (NHANES), 5823 adults were included, and leukocyte telomere length was calculated [53]. It was shown that telomeres were 15.6 base pairs smaller for every year of chronological age, and adults with high activity had higher telomere base pairs than those with moderate, low, or sedentary activity [53].

Getting older adults to do physical activity is not easy. There are multiple barriers described in the literature for them to do so. In a systematic review, it was observed that the most critical barriers included physical problems, time limits, fear of falling, lack of interest or motivation, physical limitations to walking, pain and exercising alone [54].

However, there was also improved physical condition, understanding of psychological issues, health concerns, feeling secure, and environment suitability [54]. Comparable outcomes were shown in a publication that included a study of internal and external barriers between a mid-life group (45-59 years) and a senior citizens group ( $>60$ years). It was observed that both groups had similar internal and external barriers [55]. In a sevenyear follow-up study with 1937 older adults, 286 individuals considered their physical activity to be inadequate, and in those patients, they evaluated the barriers to completing the activity [56]. It was shown that poor health, loneliness, and loss of interest were the most frequent limitations [56]. Some facts and measures are crucial to gain commitment to physical programs among the elderly. In a multiple case design study in the United Kingdom, constancy to community-based group exercise programs was studied, and the factors that were successful in maintaining adherence were the personality, professionalism, and humanized approach of the instructor, the program design, the feeling of community and the individual's perception of corporal, mental and social benefits [57].

\subsection{Mediterranean Diet in the Elderly}

The Mediterranean diet (MD) includes legumes, vegetables, fruits, whole grains, seeds, olive oil, and fish, and also involves low meat ingestion and regular drinking of wine [58]. These foods contain vitamins E and B, oleic acid, polyphenolic, and Omega-3 fatty acids [58]. According to the components of MD, in the analysis of two large studies, poultry, fish, dairy, vegetables, fruit, potatoes, cereals, olive oil, and alcohol had a positive association with the Successful Aging Index, whereas meat had an inverse association with successful aging [38,59]. Adherence to this kind of diet has multiple benefits for the elderly.

This kind of diet seems to modulate inflammation. In a cross-sectional research study with 194 elderly acute inpatients, adhesion to MD was assessed with the Italian Mediterranean Index, and it was shown that patients with low adherence had prolonged length of stay, higher levels of inflammation markers, interleukin-6, and tumor necrosis alpha [60]. Adherence to MD also has effects on mortality. In a prospective cohort report of 5200 participants older than 65 years, compliance to the MD was analyzed with the Mediterranean Diet score (MedDietScore), and for each point of increment in the score, it was related to a lower likelihood for all-cause mortality (hazard ratio $(\mathrm{HR})=0.94 ; 95 \% \mathrm{CI}=0.90-0.98$ ), coronary artery disease/cerebrovascular mortality, and non-cardiovascular/non-cancer mortality [61]. In a meta-analysis that involved 30 studies where the association between adherence to MD and mortality was studied, it was shown that mortality was inversely related to alcohol ingestion $(\mathrm{OR}=0.86 ; 95 \% \mathrm{IC}=0.77-0.97)$, fruit consumption $(\mathrm{OR}=0.88$; $95 \% \mathrm{IC}=0.83-0.94)$ and vegetable consumption $(\mathrm{OR}=0.94 ; 95 \% \mathrm{IC}=0.89-0.98)$, whereas a positive association between meat consumption and mortality was evidenced $(\mathrm{OR}=1.07$; 95\% CI = 1.01-1.13) [62].

Also, MD has positive effects on cognition and dementia. In a cross-sectional report with 79 patients older than 75 years, cohesion to MD was evaluated with the Mediterranean Diet Adherence Screener. Cognitive function was evaluated too, and it was shown that greater adherence was related to a higher Mini-Mental State Examination score. However, there was no association with the Geriatric Depression Scale [63]. Nevertheless, in a similar study with 2092 patients older than 65 years, higher adherence to MD, evaluated with the MedDietScore, was directly correlated to a better Mini-Mental State Examination and 
Geriatric Depression Scale [64]. Similar results in depression were shown in a populationbased, multi-national cross-sectional research study with 2718 elderly individuals, where greater adherence to MD was related to less chance of mental distress [65]. In a prospective long term follow up study (HELIAD study), 1865 individuals were also assessed about the adherence to MD with de MedDietScore, and a 10\% reduction in the odds for dementia per unit of increment in this score was demonstrated [66]. Also, greater compliance was linked to more enriched language, memory, and complex cognitive scores [66]. Comparable outcomes were reported in a cross-sectional research study with 279 patients older than 65 years, where MD adherence was related to a reduced chance of intellectual deterioration [57]. The Mediterranean-Dash Intervention for Neurodegenerative Delay (MIND) diet differs from the MD by designating various classes for green vegetables, berries and pastries. Also, fruits in general are not included in the MIND diet, except for berries, due to their positive effect on brain function. Fish is not prescribed daily because evidence suggests two to three times a week is adequate for neuroprotective effects [67]. This diet showed that the higher adherence slowed the rate of global cognitive decline [68] and reduced the risk of Alzheimer's disease [69].

Besides the positive effect on cognition and dementia, the MD seems to affect neurodegenerative diseases positively. In a prospective experimental study, a group of patients diagnosed with Alzheimer's Disease were asked to follow a coconut oil enhanced MD, and after three weeks, the intervention group showed advancements in incidental, temporary orientation, and grammatical memory when evaluated with an appropriate test, compared with control subjects with the same disease [66]. Despite not being a component of MD, coconut was added in this study because it can increase the ketone bodies levels, and it showed benefits in epilepsy and animal models of Parkinson's disease [58]. In a randomized controlled trial, individuals with Parkinson's disease were assigned to an individualized dietary plan, eitheron MD for 10 weeks or on control. It showed that patients' active memory, executive function, attention, language, and total cognitive assessment scores increased after the intervention compared with the control group [70].

Aging is characterized by decreased lean mass and bone mineral density, as well as insufficient protein intake leading to sarcopenia. All of these factors can contribute to frailty development $[58,71,72]$. On the other hand, adherence to MD is related to a reduced incidence of chronic illnesses and less physical deterioration in advanced years [72]. In a metaanalysis that included four studies with 5789 older people, it was shown that adherence to MD was linked to less frailty risk (OR $=0.62 ; 95 \% \mathrm{CI}=0.47-0.82, p=0.001)$ [73]. Similar results were shown in another meta-analysis with older adults in a community-dwelling with the highest adhesion to the MD associated with reduced chances of frailty $(\mathrm{OR}=0.42$; $95 \% \mathrm{CI}=0.28-0.65)$ and lower functional disability $(\mathrm{OR}=0.75 ; 95 \% \mathrm{CI}=0.61-0.93)$ [74] Also, aging is characterized by several cellular processes like telomere reduction, genomic instability, and deregulated nutrient sensing, and the MD has potential effects on these hallmarks of aging [5].

Also, adherence to MD seems to have benefits in terms of other diseases, and it has also been assessed in several populations, where it showed benefits in age-related disorders [75]. For example, in osteoarthritis, a meta-analysis evidenced that higher compliance to MD had fewer possibilities of pain exacerbation compared with lower adherence and lower risk of radiographic symptomatic knee osteoarthritis ( $R R=0.91 ; 95 \% C I=0.82-0.998)$ [76]. Also, it seems to have a positive association with quality of life [77]. Moreover, MD has cardiovascular effects. A meta-analysis evidenced that adherence to this diet reduced systolic and diastolic blood pressure levels in individuals with normal arterial pressure or mild hypertension [78]. Moreover, it was shown that a higher level of adherence to the MD is associated with a higher level of successful aging, and this effect is independent of age, sex, smoking habits, cognitive function, and inflammation levels [79]. However, on the other hand, in a randomized controlled trial with individuals at increased cardiovascular risk, the MD did not reduce heart failure incidence [80]. 
Finally, adherence to MD in non-Mediterranean countries may have some barriers. The first one is economic, as shown in a United Kingdom study [81]. In an Australian study where self-perceived barriers toward adopting MD were assessed, it was shown that behavioral control and perceived health benefits for diet quality improvement were the most prominent positive influencing factors to follow a MD. Meanwhile, dietary adherence was identified as a negative factor [82]. In a cross-sectional study in the United States, convenience, sensory factors, and health were more significant barriers for adherence to the MD in states where the incidence of stroke is higher, but not in other states [83].

\section{Practical Recommendations on Physical Activity and the Mediterranean Diet in the Elderly}

Elevating the role of nutrition and exercise at the individual and population levels is central to keeping our lives healthy and to addressing issues of global concern to an aging society. Prevention is ultimately more cost-effective than treating preventable chronic diseases. Although it is never too late, prevention begins long before one becomes an older adult. Healthy eating and regular physical exercise are among the most cost-effective, accessible, and efficient interventions capable of preventing and managing the burden of chronic diseases, reducing overall mortality, and promoting healthy aging [4].

The "Pyramid of the MD", a worldwide recognized nutritional guide, summarizes the recommendations and characteristics of the Mediterranean diet. Foods at the pyramid base should be eaten more frequently and in larger portions than those found in the higher tiers. The approximate distribution of macronutrients is $55 \%$ to $60 \%$ carbohydrates, with less than $10 \%$ simple sugars, $10 \%$ to $15 \%$ proteins, and $25 \%$ to $30 \%$ fats (mainly monounsaturated (MUFA) and polyunsaturated (PUFA), with extra virgin olive oil being the primary source). The MD pyramid is not only a balanced way of eating, which shows indications on the proportions and frequencies of food consumption, but also implies and highlights the elements of coexistence, both ecological and cultural, without forgetting the importance of drinking an adequate amount of water and undertaking physical activity [84].

Although the MD represents the general dietary and lifestyle patterns of a small proportion of the world's population, some of the basic principles that shape it, such as the preference for local and seasonal foods, the daily consumption of vegetables, fruits, whole grains, and healthy fats can be applied and adapted to other territories and cultures. This flexibility has led to its promotion in regions and its addition to dietary guidelines of countries far from its geographical origin [85].

Based on the direct relationship between adherence to the MD and health outcomes [79], at the individual level, health professionals must fulfill the role of informing and advising based on their knowledge and applicability of the nutritional recommendations of the MD to the context of each patient without imposing beliefs, preferences or ethical judgments. Therefore, it is essential to advise that personal, family, economic, and cultural circumstances must be taken into account as long as the basic criteria for the healthy eating pattern of the MD are met.

The "Global Recommendations on Physical Activity for Health" were promoted by WHO in 2010 to achieve greater physical activity levels to reduce obesity and chronic diseases. These recommendations have recently been revised. Specific instructions for physical activity for people with chronic diseases or disability were added to the suggested physical activity levels for three age groups ( 5 to 17,18 to 64 , and over 65 years of age). They are based on solid scientific evidence that shows a strong relationship between the characteristics (type, duration, and intensity) of physical activity and health outcomes [41]. From a practical perspective of the usual dialogue in the consultation, the recommendations of physical activity and MD are summarized in Table 2 [86]. 
Table 2. Recommendations on physical activity and Mediterranean Diet for successful aging: A clinician-patient Guide.

\begin{tabular}{cl}
\hline Usual Patient Questions & \multicolumn{1}{c}{ Practical Recommendations } \\
\hline & In adults, physical activity confers health benefits: Reduces general mortality and CVD. \\
Decreases the incidence of high blood pressure, T2D, and cancer. Improves symptoms of \\
anxiety and depression in addition to cognitive health and sleep.
\end{tabular}

How do I do it without hurting myself?

What amount of exercise do I require?

What exercises should I do to increase my strength?

What exercises are suitable for my equilibrium and prevent falls?

What can I do to enjoy and stick to an exercise program?

What foods and dietary recommendations are good for my health?
Basic and simple movements at the beginning and slowly increment the frequency and intensity even if you have balance or musculoskeletal problems.

The optimal amount of exercise for you is the one you can safely tolerate.

Start with an amount of exercise that you are comfortable with.

Augment more exercises gradually in order to achieve the WHO recommendation:

To benefit your health, you should engage in aerobic physical activity of at least 150-300 min of moderate intensity during the week, or 75-150 min of vigorous intensity, or a similar combination thereof.

Do strengthening activities a minimum of twice a week. This maintains or improves the strength and independence of your muscles.

To maintain or improve muscle strength, do reinforcing exercises with dumbbells or machines at least twice a week. Get off to a gentle start with sets of short repetitions of different body areas and muscle groups (trunk, upper and lower limbs).

Doing more aerobic and strengthening exercises than the least suggested has additional health benefits and improves fitness.

You must undertake (at least 3 days a week) exercises that promote functional stability and energy, improve functional ability, and avoid falls.

Simple exercises for balance, such as standing in a chair or on one leg) can preventfalls and accidents.

Stretching activities improve flexibility, balance, and joint motion.

If you have doubts about being able to do them, consult your physician or a physical therapist.

Recreational exercises can be more enjoyable and sustainable over time. According to personal preferences, the most suitable exercise is the one that gives you happiness, and you can enjoy it either alone or in the company of others.

Some people prefer group exercise and others are more inclined to individual exercise (e.g., running or swimming).

Reduce calories and increase protein intake.

Incremental fruits and vegetable intake (minimum two/five daily servings, respectively). Raise legumes ingestion.

Add more whole-grain products to your diet.

Limit you intake of fresh and processed meats. (Cold cuts: one serving or less per month and red meat: one serving weekly)

Consume unsaturated fats instead of saturated and trans fats.

Incremental fish consumption (two to three times a week) as a source of omega-3

fatty acids

Restrict ingestion of refined sugar and sugary dinks.

Reduce your sodium consumption. 


\section{Conclusions}

Aging can be a very challenging stage of life for patients and physicians. However, all of these expected changes are better controlled with early management and prevention of the common complications and health issues related to the aging process.

This review proposed practical recommendations on physical activity and the MD in the elderly. It very specifically presented safe and effective exercises that will contribute to healthier aging. In this respect, the MD has demonstrated to be superior to other diets with regard to preventing and managing common chronic diseases in aged patients.

Author Contributions: The authors' responsibilities were as follows: E.F.-T. and L.B.: were responsible for the concept of this paper and drafted the manuscript; S.C., M.d.l.A.C., D.M., A.M., D.R.-V., M.G., G.P. and G.M.: provided a critical review of the paper. All authors have read and agreed to the published version of the manuscript.

Funding: This research received no external funding.

Institutional Review Board Statement: Not applicable.

Informed Consent Statement: Not applicable.

Data Availability Statement: Not applicable.

Acknowledgments: The assistance of the staff is gratefully appreciated.

Conflicts of Interest: The authors declare no conflict of interest.

\section{References}

1. Moretti, D.; Buncuga, M.G.; Laudanno, C.D.; Quiñones, N.D.; Pasinato, C.M.S.; Rossi, F.E. PROFUND index and global subjective assessment. Prognostic value in hospitalized pluripathological patients. Medicina 2020, 80, 622-632.

2. Rowe, J.W.; Kahn, R.L. Successful Aging. Gerontologist 1997, 37, 433-440. [CrossRef] [PubMed]

3. Ruthsatz, M.; Candeias, V. Non-communicable disease prevention, nutrition and aging. Acta Biomed. 2020, 91, 379-388. [CrossRef] [PubMed]

4. Rudnicka, E.; Napierała, P.; Podfigurna, A.; Męczekalski, B.; Smolarczyk, R.; Grymowicz, M. The World Health Organization (WHO) approach to healthy ageing. Maturitas 2020, 139, 6-11. [CrossRef] [PubMed]

5. Shannon, O.M.; Ashor, A.W.; Scialo, F.; Saretzki, G.; Martin-Ruiz, C.; Lara, J.; Matu, J.; Griffiths, A.; Robinson, N.; Lillà, L.; et al. Mediterranean diet and the hallmarks of ageing. Eur. J. Clin. Nutr. 2021, 75, 1176-1192. [CrossRef] [PubMed]

6. Pataky, M.W.; Young, W.F.; Nair, K.S. Hormonal and Metabolic Changes of Aging and the Influence of Lifestyle Modifications. Mayo Clin. Proc. 2021, 96, 788-814. [CrossRef]

7. Caprara, G. Mediterranean-Type Dietary Pattern and Physical Activity: The Winning Combination to Counteract the Rising Burden of Non-Communicable Diseases (NCDs). Nutrients 2021, 13, 429. [CrossRef]

8. Diamanti-Kandarakis, E.; Dattilo, M.; Macut, D.; Duntas, L.; Gonos, E.S.; Goulis, D.; Gantenbein, C.K.; Kapetanou, M.; Koukkou, E.; Lambrinoudaki, I.; et al. MECHANISMS IN ENDOCRINOLOGY: Aging and anti-aging: A Combo-Endocrinology overview. Eur. J. Endocrinol. 2017, 176, R283-R308. [CrossRef]

9. Jones, C.M.; Boelaert, K. The Endocrinology of Ageing: A Mini-Review. Gerontology 2014, 61, 291-300. [CrossRef]

10. Veldhuis, J.D.; Sharma, A.; Roelfsema, F. Age-Dependent and Gender-Dependent Regulation of Hypothalamic-AdrenocorticotropicAdrenal Axis. Endocrinol. Metab. Clin. N. Am. 2013, 42, 201-225. [CrossRef]

11. Singh, S.; Duggal, J.; Molnar, J.; Maldonado, F.; Barsano, C.P.; Arora, R. Impact of subclinical thyroid disorders on coronary heart disease, cardiovascular and all-cause mortality: A meta-analysis. Int. J. Cardiol. 2008, 125, 41-48. [CrossRef]

12. Barbesino, G. Thyroid Function Changes in the Elderly and Their Relationship to Cardiovascular Health: A Mini-Review. Gerontology 2018, 65, 1-8. [CrossRef] [PubMed]

13. Travison, T.G.; Araujo, A.B.; Kupelian, V.; O’Donnell, A.B.; McKinlay, J.B. The Relative Contributions of Aging, Health, and Lifestyle Factors to Serum Testosterone Decline in Men. J. Clin. Endocrinol. Metab. 2006, 92, 549-555. [CrossRef]

14. Tajar, A.; Huhtaniemi, I.T.; O'Neill, T.; Finn, J.D.; Pye, S.; Lee, D.; Bartfai, G.; Boonen, S.; Casanueva, F.F.F.; Forti, G.; et al. Characteristics of Androgen Deficiency in Late-Onset Hypogonadism: Results from the European Male Aging Study (EMAS). J. Clin. Endocrinol. Metab. 2012, 97, 1508-1516. [CrossRef] [PubMed]

15. Zitzmann, M. Testosterone deficiency, insulin resistance and the metabolic syndrome. Nat. Rev. Endocrinol. $2009,5,673-681$. [CrossRef]

16. Khaw, K.-T.; Dowsett, M.; Folkerd, E.; Bingham, S.; Wareham, N.; Luben, R.; Welch, A.; Day, N. Endogenous testosterone and mortality due to all causes, cardiovascular disease, and cancer in men: European prospective investigation into cancer in Norfolk (EPIC-Norfolk) Prospective Population Study. Circulation 2007, 116, 2694-2701. [CrossRef] [PubMed] 
17. McCann, S.M.; Mastronardi, C.; De Laurentiis, A.; Rettori, V. The Nitric Oxide Theory of Aging Revisited. Ann. N. Y. Acad. Sci. 2005, 1057, 64-84. [CrossRef]

18. Batrinos, M.L. The aging of the endocrine hypothalamus and its dependent endocrine glands. Hormones 2012, 11, 241-253. [CrossRef]

19. Rodondi, N.; Elzen, W.D.; Bauer, D.C.; Cappola, A.R.; Razvi, S.; Walsh, J.; Åsvold, B.O.; Iervasi, G.; Imaizumi, M.; Collet, T.-H.; et al. Subclinical Hypothyroidism and the Risk of Coronary Heart Disease and Mortality. JAMA 2010, 304, 1365-1374. [CrossRef]

20. Wu, F.C.; Tajar, A.; Beynon, J.M.; Pye, S.; Silman, A.J.; Finn, J.D.; O'Neill, T.; Bartfai, G.; Casanueva, F.F.; Forti, G.; et al. Identification of Late-Onset Hypogonadism in Middle-Aged and Elderly Men. N. Engl. J. Med. 2010, 363, 123-135. [CrossRef]

21. Fuente, M.; Miquel, J. An Update of the Oxidation-Inflammation Theory of Aging: The Involvement of the Immune System in Oxi-Inflamm-Aging. Curr. Pharm. Des. 2009, 15, 3003-3026. [CrossRef]

22. Szic, K.S.V.; Declerck, K.; Vidaković, M.; Berghe, W.V. From inflammaging to healthy aging by dietary lifestyle choices: Is epigenetics the key to personalized nutrition? Clin. Epigenetics 2015, 7, 1-18. [CrossRef]

23. Baierle, M.; Nascimento, S.N.; Moro, A.M.; Brucker, N.; Freitas, F.; Gauer, B.; Durgante, J.; Bordignon, S.; Zibetti, M.R.; Trentini, C.M.; et al. Relationship between Inflammation and Oxidative Stress and Cognitive Decline in the Institutionalized Elderly. Oxidative Med. Cell. Longev. 2015, 2015, 1-12. [CrossRef] [PubMed]

24. De Gonzalo-Calvo, D.; Neitzert, K.; Fernández, M.; Vega-Naredo, I.; Caballero, B.; García, B.C.; Suárez, F.M.; Rodríguez-Colunga, M.J.; Solano, J.J.; Coto-Montes, A. Differential inflammatory responses in aging and disease: TNF- $\alpha$ and IL-6 as possible biomarkers. Free Radic. Biol. Med. 2010, 49, 733-737. [CrossRef] [PubMed]

25. Shanely, R.A.; Nieman, D.C.; Henson, D.A.; Jin, F.; Knab, A.M.; Sha, W. Inflammation and oxidative stress are lower in physically fit and active adults. Scand. J. Med. Sci. Sports 2011, 23, 215-223. [CrossRef] [PubMed]

26. Rodemeister, S.; Duquesne, M.; Adolph, M.; Nohr, D.; Biesalski, H.K.; Unertl, K. Massive and long-lasting decrease in vitamin C plasma levels as a consequence of extracorporeal circulation. Nutrition 2014, 30, 673-678. [CrossRef]

27. Shakiba, Y.; Mahmoudi, M. Chronic Inflammation and Oxidative Stress as a Major Cause of Age-Related Diseases and Cancer. Recent Pat. Inflamm. Allergy Drug Discov. 2009, 3, 73-80. [CrossRef]

28. El Assar, M.; Angulo, J.; Rodríguez-Mañas, L. Oxidative stress and vascular inflammation in aging. Free Radic. Biol. Med. 2013, 65, 380-401. [CrossRef]

29. Liguori, I.; Russo, G.; Curcio, F.; Bulli, G.; Aran, L.; DELLA Morte, D.; Gargiulo, G.; Testa, G.; Cacciatore, F.; Bonaduce, D.; et al. Oxidative stress, aging, and diseases. Clin. Interv. Aging 2018, 13, 757-772. [CrossRef]

30. Can, B.; Kara, O.; Kizilarslanoglu, M.C.; Arik, G.; Aycicek, G.S.; Sumer, F.; Civelek, R.; Demirtas, C.; Ulger, Z. Serum markers of inflammation and oxidative stress in sarcopenia. Aging Clin. Exp. Res. 2016, 29, 745-752. [CrossRef]

31. Pizent, A.; Pavlovic, M.; Jurasovic, J.; Dodig, S.; Pasalic, D.; Mujagic, R. Antioxidants, trace elements and metabolic syndrome in elderly subjects. J. Nutr. Health Aging 2010, 14, 866-871. [CrossRef]

32. Milanesi, E.; Manda, G.; Dobre, M.; Codrici, E.; Neagoe, I.V.; Popescu, B.O.; Bajenaru, O.A.; Spiru, L.; Tudose, C.; Prada, G.-I.; et al. Distinctive Under-Expression Profile of Inflammatory and Redox Genes in the Blood of Elderly Patients with Cardiovascular Disease. J. Inflamm. Res. 2021, 14, 429-442. [CrossRef]

33. Safdar, A.; Hamadeh, M.J.; Kaczor, J.J.; Raha, S.; Debeer, J.; Tarnopolsky, M.A. Aberrant Mitochondrial Homeostasis in the Skeletal Muscle of Sedentary Older Adults. PLoS ONE 2010, 5, e10778. [CrossRef] [PubMed]

34. Cesari, M.; Pahor, M.; Bartali, B.; Cherubini, A.; Penninx, B.W.J.H.; Williams, G.R.; Atkinson, H.; Martin, A.; Guralnik, J.M.; Ferrucci, L. Antioxidants and physical performance in elderly persons: The Invecchiare in Chianti (InCHIANTI) study. Am. J. Clin. Nutr. 2004, 79, 289-294. [CrossRef]

35. Tamura, Y.; Omura, T.; Toyoshima, K.; Araki, A. Nutrition Management in Older Adults with Diabetes: A Review on the Importance of Shifting Prevention Strategies from Metabolic Syndrome to Frailty. Nutrients 2020, 12, 3367. [CrossRef] [PubMed]

36. Tucker, L.A. Physical activity and telomere length in U.S. men and women: An NHANES investigation. Prev. Med. 2017, 100, 145-151. [CrossRef]

37. Bartlett, D.B.; Willis, L.H.; Slentz, C.A.; Hoselton, A.; Kelly, L.; Huebner, J.L.; Kraus, V.B.; Moss, J.; Muehlbauer, M.J.; Spielmann, G.; et al. Ten weeks of high-intensity interval walk training is associated with reduced disease activity and improved innate immune function in older adults with rheumatoid arthritis: A pilot study. Arthritis Res. 2018, 20, 1-15. [CrossRef] [PubMed]

38. Bartlett, D.B.; Slentz, C.A.; Willis, L.H.; Hoselton, A.; Huebner, J.L.; Kraus, V.B.; Moss, J.; Muehlbauer, M.J.; Spielmann, G.; Muoio, D.M.; et al. Rejuvenation of Neutrophil Functions in Association With Reduced Diabetes Risk Following Ten Weeks of Low-Volume High Intensity Interval Walking in Older Adults With Prediabetes-A Pilot Study. Front. Immunol. $2020,11$. [CrossRef] [PubMed]

39. Martucci, M.; Ostan, R.; Biondi, F.; Bellavista, E.; Fabbri, C.; Bertarelli, C.; Salvioli, S.; Capri, M.; Franceschi, C.; Santoro, A. Mediterranean diet and inflammaging within the hormesis paradigm. Nutr. Rev. 2017, 75, 442-455. [CrossRef]

40. Santoro, A.; Martucci, M.; Conte, M.; Capri, M.; Franceschi, C.; Salvioli, S. Inflammaging, hormesis and the rationale for anti-aging strategies. Ageing Res. Rev. 2020, 64, 101142. [CrossRef] [PubMed] 
41. Bull, F.C.; Al-Ansari, S.S.; Biddle, S.; Borodulin, K.; Buman, M.P.; Cardon, G.; Carty, C.; Chaput, J.-P.; Chastin, S.; Chou, R.; et al. World Health Organization 2020 guidelines on physical activity and sedentary behaviour. Br. J. Sports Med. 2020, 54, 1451-1462. [CrossRef] [PubMed]

42. Department of Health UK. Physical Activity Guidelines for Adults (65+Years); Department of Health: London, UK, 2011 ; Volume 11. Available online: https://www.gov.uk/government/uploads/system/uploads/attachment_data/file/213740/dh_128145.pdf (accessed on 2 June 2021).

43. Talar, K.; Hernández-Belmonte, A.; Vetrovsky, T.; Steffl, M.; Kałamacka, E.; Courel-Ibáñez, J. Benefits of Resistance Training in Early and Late Stages of Frailty and Sarcopenia: A Systematic Review and Meta-Analysis of Randomized Controlled Studies. J. Clin. Med. 2021, 10, 1630. [CrossRef] [PubMed]

44. Haider, S.; Grabovac, I.; Dorner, T.E. Effects of physical activity interventions in frail and prefrail community-dwelling people on frailty status, muscle strength, physical performance and muscle mass-A narrative review. Wien. Klin. Wochenschr. 2019, 131, 244-254. [CrossRef] [PubMed]

45. Marzetti, E.; on behalf of the SPRINTT Consortium; Calvani, R.; Tosato, M.; Cesari, M.; Di Bari, M.; Cherubini, A.; Broccatelli, M.; Savera, G.; D'Elia, M.; et al. Physical activity and exercise as countermeasures to physical frailty and sarcopenia. Aging Clin. Exp. Res. 2017, 29, 35-42. [CrossRef]

46. Nagai, K.; Miyamato, T.; Okamae, A.; Tamaki, A.; Fujioka, H.; Wada, Y.; Uchiyama, Y.; Shinmura, K.; Domen, K. Physical activity combined with resistance training reduces symptoms of frailty in older adults: A randomized controlled trial. Arch. Gerontol. Geriatr. 2018, 76, 41-47. [CrossRef]

47. Jia, R.-X.; Liang, J.-H.; Xu, Y.; Wang, Y.-Q. Effects of physical activity and exercise on the cognitive function of patients with Alzheimer disease: A meta-analysis. BMC Geriatr. 2019, 19, 181. [CrossRef]

48. An, H.-Y.; Chen, W.; Wang, C.-W.; Yang, H.-F.; Huang, W.-T.; Fan, S.-Y. The Relationships between Physical Activity and Life Satisfaction and Happiness among Young, Middle-Aged, and Older Adults. Int. J. Environ. Res. Public Health 2020, $17,4817$. [CrossRef]

49. Lee, K.; So, W.-Y. Differences in the Levels of Physical Activity, Mental Health, and Quality of Life of Elderly Koreans with Activity-Limiting Disabilities. Int. J. Environ. Res. Public Health 2019, 16, 2736. [CrossRef]

50. Lok, N.; Lok, S.; Canbaz, M. The effect of physical activity on depressive symptoms and quality of life among elderly nursing home residents: Randomized controlled trial. Arch. Gerontol. Geriatr. 2017, 70, 92-98. [CrossRef]

51. Kehler, D.S.; Theou, O. The impact of physical activity and sedentary behaviors on frailty levels. Mech. Ageing Dev. 2019, 180, 29-41. [CrossRef]

52. Ogawa, E.F.; Leveille, S.G.; Wright, J.A.; Shi, L.; Camhi, S.M.; You, T. Physical Activity Domains/Recommendations and Leukocyte Telomere Length in U.S. Adults. Med. Sci. Sports Exerc. 2017, 49, 1375-1382. [CrossRef] [PubMed]

53. Yarmohammadi, S.; Saadati, H.M.; Ghaffari, M.; Ramezankhani, A. A systematic review of barriers and motivators to physical activity in elderly adults in Iran and worldwide. Epidemiol. Health 2019, 41, e2019049. [CrossRef] [PubMed]

54. Justine, M.; Azizan, A.; Hassan, V.; Salleh, Z.; Manaf, H. Barriers to participation in physical activity and exercise among middle-aged and elderly individuals. Singap. Med. J. 2013, 54, 581-586. [CrossRef] [PubMed]

55. Moschny, A.; Platen, P.; Klaassen-Mielke, R.; Trampisch, U.; Hinrichs, T. Barriers to physical activity in older adults in Germany: A cross-sectional study. Int. J. Behav. Nutr. Phys. Act. 2011, 8, 121. [CrossRef] [PubMed]

56. Killingback, C.; Tsofliou, F.; Clark, C. Older people's adherence to community-based group exercise programmes: A multiple-case study. BMC Public Health 2017, 17, 115. [CrossRef] [PubMed]

57. De Amicis, R.; Leone, A.; Foppiani, A.; Osio, D.; Lewandowski, L.; Giustizieri, V.; Cornelio, P.; Cornelio, F.; Imperatori, S.F.; Cappa, S.F.; et al. Mediterranean Diet and Cognitive Status in Free-Living Elderly: A Cross-Sectional Study in Northern Italy. J. Am. Coll. Nutr. 2018, 37, 494-500. [CrossRef]

58. Buglio, A.L.; Bellanti, F.; Capurso, C.; Paglia, A.; Vendemiale, G. Adherence to Mediterranean Diet, Malnutrition, Length of Stay and Mortality in Elderly Patients Hospitalized in Internal Medicine Wards. Nutrients 2019, 11, 790. [CrossRef]

59. Foscolou, A.; Koloverou, E.; Matalas, A.-L.; Tyrovolas, S.; Chrysohoou, C.; Sidossis, L.; Rallidis, L.; Panagiotakos, D.B. Decomposition of Mediterranean Dietary Pattern on Successful Aging, Among Older Adults: A Combined Analysis of Two Epidemiological Studies. J. Aging Health 2018, 31, 1549-1567. [CrossRef]

60. Bonaccio, M.; Di Castelnuovo, A.; Costanzo, S.; Gialluisi, A.; Persichillo, M.; Cerletti, C.; Donati, M.B.; de Gaetano, G.; Iacoviello, L. Mediterranean diet and mortality in the elderly: A prospective cohort study and a meta-analysis. Br. J. Nutr. 2018, 120, 841-854. [CrossRef] [PubMed]

61. Eleftheriou, D.; Benetou, V.; Trichopoulou, A.; La Vecchia, C.; Bamia, C. Mediterranean diet and its components in relation to all-cause mortality: Meta-analysis. Br. J. Nutr. 2018, 120, 1081-1097. [CrossRef]

62. Hernández-Galiot, A.; Goñi, I. Adherence to the Mediterranean diet pattern, cognitive status and depressive symptoms in an elderly non-institutionalized population. Nutr. Hosp. 2017, 34, 338-344. [CrossRef] [PubMed]

63. Mantzorou, M.; Vadikolias, K.; Pavlidou, E.; Tryfonos, C.; Vasios, G.; Serdari, A.; Giaginis, C. Mediterranean diet adherence is associated with better cognitive status and less depressive symptoms in a Greek elderly population. Aging Clin. Exp. Res. 2020, 33, 1033-1040. [CrossRef] 
64. Masana, M.F.; Haro, J.M.; Mariolis, A.; Piscopo, S.; Valacchi, G.; Bountziouka, V.; Anastasiou, F.; Zeimbekis, A.; Tyrovola, D.; Gotsis, E.; et al. Mediterranean diet and depression among older individuals: The multinational MEDIS study. Exp. Gerontol. 2018, 110, 67-72. [CrossRef] [PubMed]

65. Anastasiou, C.A.; Yannakoulia, M.; Kosmidis, M.; Dardiotis, E.; Hadjigeorgiou, G.M.; Sakka, P.; Arampatzi, X.; Bougea, A.; Labropoulos, I.; Scarmeas, N. Mediterranean diet and cognitive health: Initial results from the Hellenic Longitudinal Investigation of Ageing and Diet. PLoS ONE 2017, 12, e0182048. [CrossRef] [PubMed]

66. Ortí, J.E.D.L.R.; García-Pardo, M.P.; Drehmer, E.; Cantus, D.S.; Rochina, M.J.; Aguilar, M.A.; Yang, I.H. Improvement of Main Cognitive Functions in Patients with Alzheimer's Disease after Treatment with Coconut Oil Enriched Mediterranean Diet: A Pilot Study. J. Alzheimer's Dis. 2018, 65, 577-587. [CrossRef] [PubMed]

67. Hosking, D.E.; Eramudugolla, R.; Cherbuin, N.; Anstey, K.J. MIND not Mediterranean diet related to 12-year incidence of cognitive impairment in an Australian longitudinal cohort study. Alzheimer's Dement. 2019, 15, 581-589. [CrossRef]

68. Cherian, L.; Wang, Y.; Fakuda, K.; Leurgans, S.; Aggarwal, N.; Morris, M. Mediterranean-dash intervention for neurodegenerative delay (mind) diet slows cognitive decline after stroke. J. Prev. Alzheimer's Dis. 2019, 6, 1-7. [CrossRef]

69. Morris, M.C.; Tangney, C.C.; Wang, Y.; Sacks, F.M.; Bennett, D.A.; Aggarwal, N.T. MIND diet associated with reduced incidence of Alzheimer's disease. Alzheimer's Dement. 2015, 11, 1007-1014. [CrossRef]

70. Paknahad, Z.; Sheklabadi, E.; Derakhshan, Y.; Bagherniya, M.; Chitsaz, A. The effect of the Mediterranean diet on cognitive function in patients with Parkinson's disease: A randomized clinical controlled trial. Complement. Ther. Med. 2020, 50, 102366. [CrossRef]

71. Tarazona-Santabalbina, F.J.; Gómez-Cabrera, M.C.; Pérez-Ros, P.; Martínez-Arnau, F.M.; Cabo, H.; Tsaparas, K.; Salvador-Pascual, A.; Rodríguez-Mañas, L.; Viña, J. A Multicomponent Exercise Intervention that Reverses Frailty and Improves Cognition, Emotion, and Social Networking in the Community-Dwelling Frail Elderly: A Randomized Clinical Trial. J. Am. Med. Dir. Assoc. 2016, 17, 426-433. [CrossRef]

72. Capurso, C.; Bellanti, F.; Buglio, A.L.; Vendemiale, G. The Mediterranean Diet Slows Down the Progression of Aging and Helps to Prevent the Onset of Frailty: A Narrative Review. Nutrients 2019, 12, 35. [CrossRef]

73. Kojima, G.; Avgerinou, C.; Iliffe, S.; Walters, K. Adherence to Mediterranean Diet Reduces Incident Frailty Risk: Systematic Review and Meta-Analysis. J. Am. Geriatr. Soc. 2018, 66, 783-788. [CrossRef]

74. Silva, R.; Pizato, N.; Da Mata, F.; Figueiredo, A.; Ito, M.; Pereira, M.G. Mediterranean Diet and Musculoskeletal-Functional Outcomes in Community-Dwelling Older People: A Systematic Review and Meta-Analysis. J. Nutr. Health Aging 2017, 22, 655-663. [CrossRef] [PubMed]

75. Critselis, E.; Panagiotakos, D. Adherence to the Mediterranean diet and healthy ageing: Current evidence, biological pathways, and future directions. Crit. Rev. Food Sci. Nutr. 2019, 60, 2148-2157. [CrossRef] [PubMed]

76. Veronese, N.; Koyanagi, A.; Stubbs, B.; Cooper, C.; Guglielmi, G.; Rizzoli, R.; Punzi, L.; Rogoli, D.; Caruso, M.G.; Rotolo, O.; et al. Mediterranean diet and knee osteoarthritis outcomes: A longitudinal cohort study. Clin. Nutr. 2019, 38, 2735-2739. [CrossRef] [PubMed]

77. Morales-Ivorra, I.; Romera-Baures, M.; Roman-Viñas, B.; Serra-Majem, L. Osteoarthritis and the Mediterranean Diet: A Systematic Review. Nutrients 2018, 10, 1030. [CrossRef]

78. Nissensohn, M.; Roman-Viñas, B.; Villegas, A.S.; Piscopo, S.; Serra-Majem, L. The Effect of the Mediterranean Diet on Hypertension: A Systematic Review and Meta-Analysis. J. Nutr. Educ. Behav. 2016, 48, 42-53.e1. [CrossRef]

79. Foscolou, A.; D’Cunha, N.M.; Naumovski, N.; Tyrovolas, S.; Chrysohoou, C.; Rallidis, L.; Polychronopoulos, E.; Matalas, A.-L.; Sidossis, L.S.; Panagiotakos, D. The association between the level of adherence to the Mediterranean diet and successful aging: An analysis of the ATTICA and MEDIS (MEDiterranean Islands Study) epidemiological studies. Arch. Gerontol. Geriatr. 2020, 89, 104044. [CrossRef]

80. Papadaki, A.; Martinez-Gonzalez, M.A.; Alonso-Gómez, A.; Rekondo, J.; Salas-Salvadó, J.; Corella, D.; Ros, E.; Fitó, M.; Estruch, R.; Lapetra, J.; et al. Mediterranean diet and risk of heart failure: Results from the PREDIMED randomized controlled trial. Eur. J. Heart Fail. 2017, 19, 1179-1185. [CrossRef]

81. Tong, T.Y.N.; Imamura, F.; Monsivais, P.; Brage, S.; Griffin, S.J.; Wareham, N.J.; Forouhi, N.G. Dietary cost associated with adherence to the Mediterranean diet, and its variation by socio-economic factors in the UK Fenland Study. Br. J. Nutr. 2018, 119, 685-694. [CrossRef]

82. Scannell, N.; Villani, A.; Mantzioris, E.; Swanepoel, L. Understanding the Self-Perceived Barriers and Enablers toward Adopting a Mediterranean Diet in Australia: An Application of the Theory of Planned Behaviour Framework. Int. J. Environ. Res. Public Health 2020, 17, 9321. [CrossRef] [PubMed]

83. Knight, C.J.; Jackson, O.; Rahman, I.; Burnett, D.O.; Frugé, A.D.; Greene, M.W. The Mediterranean Diet in the Stroke Belt: A Cross-Sectional Study on Adherence and Perceived Knowledge, Barriers, and Benefits. Nutrients 2019, 11, 1847. [CrossRef] [PubMed]

84. Bach-Faig, A.; Berry, E.M.; Lairon, D.; Reguant, J.; Trichopoulou, A.; Dernini, S.; Medina, F.X.; Battino, M.; Belahsen, R.; Miranda, G.; et al. Mediterranean diet pyramid today. Science and cultural updates. Public Health Nutr. 2011, 14, $2274-2284$. [CrossRef] [PubMed] 
85. Lăcătușu, C.-M.; Grigorescu, E.-D.; Floria, M.; Onofriescu, A.; Mihai, B.-M. The Mediterranean Diet: From an Environment-Driven Food Culture to an Emerging Medical Prescription. Int. J. Environ. Res. Public Health 2019, 16, 942. [CrossRef]

86. Heyn, P.C.; Hirsch, M.A.; York, M.K.; Backus, D. Physical Activity Recommendations for the Aging Brain: A Clinician-Patient Guide. Arch. Phys. Med. Rehabil. 2016, 97, 1045-1047. [CrossRef] [PubMed] 